2019-05-15

\title{
Trace elements in laundry dryer lint: A proxy for household contamination and discharges to waste water.
}

\section{Turner, Andrew}

http://hdl.handle.net/10026.1/13398

\subsection{6/j.scitotenv.2019.02.025}

Science of the Total Environment

Elsevier

All content in PEARL is protected by copyright law. Author manuscripts are made available in accordance with publisher policies. Please cite only the published version using the details provided on the item record or document. In the absence of an open licence (e.g. Creative Commons), permissions for further reuse of content should be sought from the publisher or author. 
1

.

\section{Trace elements in laundry dryer lint: a proxy for household contamination and discharges to waste water}

3

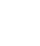

5

6

7

8

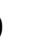

Keywords:

Dryer lint; microfibres; XRF; trace elements; antimony; brominated compounds

*School of Geography, Earth and Environmental Sciences,

University of Plymouth

Drake Circus

Plymouth PL4 8AA, UK

aturner@plymouth.ac.uk 
Abstract

Seventy samples of laundry dryer lint from 19 households have been analysed for trace elements ( $\mathrm{As}, \mathrm{Br}, \mathrm{Cu}, \mathrm{Fe}, \mathrm{Ni}, \mathrm{Pb}, \mathrm{Sb}, \mathrm{Zn}$ ) by energy-dispersive portable x-ray fluorescence (XRF) spectrometry. Bromine, Fe and $\mathrm{Zn}$ were detected in more than sixty samples encompassing all households, with dry weight concentrations ranging from 5.5 to $213 \mu \mathrm{g} \mathrm{g} \mathrm{g}^{-1}, 76$ to $3580 \mu \mathrm{g} \mathrm{g}^{-1}$ and 24 to $3540 \mu \mathrm{g} \mathrm{g}^{-1}$, respectively. Lead and Sb were detected in twenty and eight samples from ten and seven households, respectively, with respective concentrations ranging from about 8 to $110 \mu \mathrm{g} \mathrm{g}^{-1}$ for $\mathrm{Pb}$ and 40 to $90 \mu \mathrm{g} \mathrm{g}^{-1}$ for Sb. In contrast, As was only detected in six samples from the same household with concentrations ranging from about 10 to $250 \mu \mathrm{g} \mathrm{g}^{-1}$. Analysis of 72 items of new or clean clothing and linen revealed the ubiquity of Sb in synthetic (largely polyester-based) articles and the presence of $\mathrm{Br}$ in a variety of natural and synthetic articles, suggesting that the dominant source of these elements in dryer lint is derived from clothing fibres themselves; specifically, $\mathrm{Sb}_{2} \mathrm{O}_{3}$ is employed as a catalyst in the manufacture of polyester and various brominated compounds appear to be used as disperse dyes. No detectable $\mathrm{As}$ or $\mathrm{Pb}$ in the clothing-linen samples indicates that their presence in dryer lint arises from contamination of laundry from extraneous sources (e.g. household dust and material accumulated from outdoor activities) and suggests that concentrations can be used as proxies for exposure or household contamination. Since dryer lint is representative of material shed during the washing of clothes and linen, its composition also serves as a proxy for contaminants entering the environment from this process. Of particular significance in this respect is the discharge of chemicals specific to textiles and associated with microfibers.

\section{Introduction}

Laundry lint is generated during the drying of clothes and linen in a clothes dryer and accumulates on a screen or filter. Lint is composed of fibres of clothing-linen as well as extraneous material that is associated with laundry, like dust, pollen, skin, hair, food, microorganisms and soil, and, potentially, residues of laundry detergent.

Mahaffy et al. (1998) proposed using dryer lint as a novel and non-invasive proxy of household contamination and non-dietary exposure since samples are readily collected and material on clothing may reflect a composite of individual chemical sources within and external to the household. To this end, the authors determined the concentration of $\mathrm{Pb}$ in dryer lint samples collected by participants from three different groups: a control, comprising university members of 
staff with no known occupational or recreational exposure to the metal; an urban composite, consisting of samples taken from communal dryers in a city centre; and an occupational, made up of radiator shop employees whose managers were aware of potentially high $\mathrm{Pb}$ exposure. Arithmetic mean values of $\mathrm{Pb}$ in lint were about $20 \mu \mathrm{g} \mathrm{g}^{-1}$ for the former groups and about $60 \mu \mathrm{g} \mathrm{g}^{-1}$ for secondary radiator shop employees (i.e. clerical or managerial staff) and $350 \mathrm{\mu g} \mathrm{g}^{-1}$ for primary shop employees (i.e. those directly involved with soldering). Some participants or family members of the latter category exhibited $\mathrm{Pb}$ blood levels above recommended action thresholds.

Stapleton et al. (2005) analysed samples of domestic dryer lint and detected various brominated flame retardants. Their presence was attributed to household dust (and associated flame retardants) being picked up by clothing, although contributions from the dryers themselves could not be ruled out. More recently, Ouyang et al. (2017) tentatively identified a spectrum of chemicals in domestic laundry dryer lint that included pesticides, therapeutic and illicit drugs, fragrances, plasticizers and compound metabolites. Significantly, the concentrations of some compounds, including one commonly employed as an insect repellent, were considerably higher in lint than in household dust.

Given that the composition of dryer lint reflects the signature of chemicals shed in solid form (and mainly as fibrous microplastics) from the washing of clothes and linen, analysis of lint can also be used to gain semi-quantitative information on chemicals discharged to the environment from this process. Thus, while there has been considerable recent interest in laundry as a source of microplastics to water treatment plants and aquatic systems (Hernandez et al., 2017; Almroth et al., 2018), analysis of lint may afford a simple means of chemically characterising these plastics.

In the present study, domestic dryer lint samples have been analysed for a broad suite of environmentally relevant and potentially toxic trace elements by portable $\mathrm{x}$-ray fluorescence (XRF) spectrometry, a non-destructive, multi-element technique that entails minimal sample preparation and is capable of a high throughput of samples. Specifically, the instrument is configured in a low density mode that has previously been applied to plastics, foams and biological material (Turner and Solman, 2016; Bull et al., 2017; Massos and Turner, 2017) and that is validated through independent sample measurements by inductively coupled plasma (ICP) spectrometry following acid digestion. In addition, and in order to evaluate the relative significance of different sources of trace elements to the lint, articles of clothing and linen, constructed of both synthetic and natural fibres, have been analysed by the same approach. The results are discussed in terms of the use of dryer lint as a potential indicator of household contamination and human exposure and as a measure of chemicals that are lost to the environment through washing. 


\section{Methods}

\subsection{Sampling and sample preparation}

A total of nineteen households within $80 \mathrm{~km}$ of Plymouth (south west England), and encompassing urban, suburban, rural and agricultural settings, provided between one and eight samples of lint from individual operations of domestic vented or condenser tumble dryers. Samples were collected manually from lint filters immediately after dryer use in clear polyethylene bags or brown envelopes and information was supplied on any particular articles laundered or any specific recent activities of household occupants. The load of clothing dried was measured by some participants and ranged from about 2.5 to $4.5 \mathrm{~kg}$ on a dry weight basis.

In the laboratory, individual lint samples were weighed on a Sartorius Genius five-figure balance and coded according to colour. Samples were then packed in to polyethylene XRF sample cups (Chemplex series 1400; 21-mm internal diameter) to a depth of $20 \mathrm{~mm}$ (the critical depth for plastics is $~ 5$ to $10 \mathrm{~mm}$; Niton, 2011) and collar-sealed with $3.6 \mu \mathrm{m}$ SpectraCertified Mylar polyester film (Figure 1). For samples too small to completely fill the XRF cups, quartz wool was added beneath the lint such that the sample was in full contact with the polyester film and at a depth of at least $10 \mathrm{~mm}$.

\subsection{XRF analysis}

Samples were analysed for a suite of elements, of which the trace elements: $\mathrm{As}, \mathrm{Br}, \mathrm{Cu}, \mathrm{Fe}, \mathrm{Ni}, \mathrm{Pb}$, $\mathrm{Sb}, \mathrm{Zn}$; are the focus of the present study, using a battery-operated, energy-dispersive Niton XL3t $950 \mathrm{He}$ GOLDD+ portable XRF spectrometer. The instrument was configured nose upwards in a shielded laboratory test-stand and activated remotely by a laptop via USB connection. Samples were placed centrally, and with the polyester film facing downwards, over the $8 \mathrm{~mm}\left(50 \mathrm{~mm}^{2}\right) \mathrm{x}$-ray beam before being counted for 60 seconds in a low density, standardless plastics mode ( 40 seconds at 40 $\mu \mathrm{A}$ and $50 \mathrm{kVp}$ and 20 seconds at $100 \mu \mathrm{A}$ and $20 \mathrm{kVp}$ ). Measurements were then repeated at four different locations towards the perimeter of each sample surface. Spectra arising from sample counting were quantified by fundamental parameter coefficients to yield elemental concentrations in $\mu \mathrm{g} \mathrm{g}^{-1}$ and a measurement error of $2 \sigma$ (95\% confidence) that were downloaded to the laptop via Niton data transfer software. For quality assurance and instrument performance purposes, two 13 mm-thick Niton reference plastics that had been impregnated with various elements (PN 180-554 batch SN PE-071-N: $\mathrm{Br}=495 \pm 20 \mu \mathrm{g} \mathrm{g}^{-1}, \mathrm{~Pb}=1002 \pm 40 \mu \mathrm{g} \mathrm{g}^{-1}$; PN 180-619 LOT\#T-18: As $=50 \pm 7 \mu \mathrm{g} \mathrm{g}^{-1}$, $\mathrm{Pb}=150 \pm 12 \mu \mathrm{g} \mathrm{g}^{-1}, \mathrm{Sb}=96 \pm 10 \mu \mathrm{g} \mathrm{g} \mathrm{g}^{-1}$ ) were analysed at regular intervals throughout each 
measurement session, with concentrations returned by the XRF always within $10 \%$ of corresponding certified values.

Measurement limits of detection, based on three counting errors, varied among the elements and samples because of variations in sample composition but mean values ranged from $<10 \mu \mathrm{g} \mathrm{g}^{-1}$ for $\mathrm{As}, \mathrm{Br}$ and $\mathrm{Pb}$ to $>70 \mu \mathrm{g} \mathrm{g}^{-1}$ for Fe. Measurement precision, based on quintuplicate readings of the same sample and at the same location with respect to the detector, was better than $10 \%$ for all elements with the exception of $\mathrm{Br}, \mathrm{Cu}$ and $\mathrm{Pb}(<15 \%)$.

In addition, 72 items of clothing and linen were analysed by XRF. Here, new or freshly washed items constructed of (mainly) cotton, wool or polyester or mixtures thereof, and including shirts, blouses, trousers, skirts, underwear, jackets, fleeces, scarves, gloves, hats, sportswear, towels, tablecloths and bedsheets, were gathered to a depth of at least $10 \mathrm{~mm}$ onto a plate of clear glass on a solid floor. The nose of the XRF spectrometer, shielded with a PVC-tungsten collar, was pressed firmly against the measurement surface and activated by hand and using the trigger mechanism under the conditions and times specified above.

\subsection{Validation of XRF measurements using ICP}

In order to evaluate the performance of the XRF on lint samples, including any interferences arising from the presence of air in the matrix, five samples were subsequently acid-digested and analysed by inductively coupled plasma-optical emission spectrometry (ICP-OES). Briefly, triplicate $250 \mathrm{mg}$ subsamples were weighed into $50 \mathrm{ml}$ Pyrex beakers to which $3 \mathrm{ml}$ concentrated $\mathrm{HNO}_{3}$ and $3 \mathrm{ml}$ concentrated $\mathrm{HCl}$ were added. Beakers were covered with watch glasses and left for $2 \mathrm{~h}$ before being simmered for a further $2 \mathrm{~h}$ on a hot plate, with additions of acid undertaken as necessary to maintain a near-constant digest volume. After cooling, the contents were filtered into volumetric flasks and diluted to $50 \mathrm{ml}$ with distilled deionised water. Digests were analysed for $\mathrm{As}, \mathrm{Br}, \mathrm{Cu}, \mathrm{Fe}, \mathrm{Ni}$, $\mathrm{Pb}, \mathrm{Sb}$ and $\mathrm{Zn}$ using a Thermo Scientific iCAP 7000 Series ICP Spectrometer calibrated with matrixmatched mixed standards and blanks.

A comparison of results arising from ICP and XRF, shown in Figure 2, reveals overall agreement within $12 \%$ and a Pearson' moment correlation coefficient defining the data of close to unit value.

\section{Results}

148 A total of 70 dryer lint samples were analysed as part of the study, with dry weights ranging from 149 about 0.2 to $3 \mathrm{~g}$. Given the clothing loads reported, it is estimated that lint arising from tumble 
drying represents between about 0.02 and $0.1 \%$ of the mass of material processed; that is, up to a few parts per thousand of each load is lost via lint. Sample colour was usually grey or off-white, but shades of blue, pink and purple were evident in many cases and occasional samples were brown (Figure 1). Colours varied between samples from the same participant suggesting that the types of and colours clothing or linen dictate the precise colour of the final material.

Regarding elemental concentrations returned by the XRF, the relative standard deviation arising from five measurements taken at different locations on the same sample surface was less than $25 \%$ but always greater than the respective measurement precision. This may be partly the result of inconsistencies in sample thickness or the presence of fold-lines arising from manual packing but is largely attributed to an inherent heterogeneity within the material. Such heterogeneity was most evident where samples exhibited small but visible colour or textural transitions beneath the polyester film, an effect that may have resulted from uneven distribution of material across the lint filter or some cross contamination of lint between drying loads.

Table 1 summarises the number of positives and concentrations for each element both per household and on an individual sample basis. The latter are based on the mean of five measurements performed at different locations on the same sample while the former is based on an average of mean measurements on multiple samples (or, in some cases, a single sample) from the same participant. The two measures are different, therefore, because different numbers of samples were taken among the households and some elements may have been detected in differing numbers of cases within the same household. For example, Cu was detected in 46 samples among 17 households, with a maximum average concentration per household of $264 \mu \mathrm{g} \mathrm{g}^{-1}$ but a maximum individual sample concentration of $456 \mu \mathrm{g} \mathrm{g}^{-1}$.

Overall, $\mathrm{Br}$, Fe and $\mathrm{Zn}$ were detected in all households, and $\mathrm{Zn}$ was detected in all samples. In contrast, $\mathrm{Sb}$ was detected in seven samples from six different households, Ni in six samples from six different households and As in six samples from the same household. With the exception of the latter three elements, concentrations were highly variable among households and samples, with a range spanning at least one order of magnitude in most cases. Significant associations were limited to $\mathrm{Cu}-\mathrm{Ni}(r=0.88 ; n=6)$ and $\mathrm{Cu}-\mathrm{Fe}(r=0.77 ; n=38)$ and there was no clear relationship between trace element concentrations and sample colour or mass. Shown in Table 2 are summary statistics for trace elements in the new or cleaned clothing and linen samples. Antimony and $\mathrm{Br}$ were detected in almost one half of all samples tested and Fe was detectable in 25 cases; among these elements, concentrations were variable and spanned at least an order of magnitude, and mean, median and maximum concentrations of $\mathrm{Sb}$ and $\mathrm{Br}$ were higher than 
respective values for the lint samples on either a household or sample basis. In contrast, concentrations of $\mathrm{Cu}, \mathrm{Ni}$ and $\mathrm{Zn}$ were returned in less than ten clothing-linen samples each while neither $\mathrm{As}$ nor $\mathrm{Pb}$ were detected throughout. There were no significant associations between the elements in clothing-linen articles, and while $\mathrm{Sb}$ and $\mathrm{Br}$ coexisted in 22 samples, combinations of any of the remaining elements were only observed in four items of clothing.

A comparison of clothing-linen and lint was made for each trace element by dividing the sum of concentrations in the former by the sum of concentrations in the latter, with resulting ratios shown in Table 2. Comparisons are semi-quantitative because of the different numbers of samples in each category and different XRF detection limits among the elements studied. Nevertheless, high ratios for $\mathrm{Br}$ and, in particular, Sb, signify that clothing-linen itself is the dominant source of these elements to dryer lint while values close or equal to $0(\mathrm{As}$ and $\mathrm{Pb}$ ) signify the presence of these elements in lint solely from extraneous sources.

Concentrations of trace elements in dryer lint are comparable with the limited number of published concentrations in the literature. Thus, Mahaffy et al. (1998) report acid-digestible dry weight concentrations of $\mathrm{Pb}$ ranging from 6 to $110 \mu \mathrm{g} \mathrm{g}^{-1}$ and a mean of about $20 \mu \mathrm{g} \mathrm{g}^{-1}$ in samples collected from homes of 20 university staff with no known occupational or recreational origins of the metal; additional samples from communal dryers for low income inner city communities ranged from 6 to $55 \mu \mathrm{g} \mathrm{g}^{-1}$. Ene-Parent and Zikovsky (2001) determined various elements in ten samples of lint from "white-collar" households by neutron activation analysis, with $\mathrm{Br}, \mathrm{Cu}, \mathrm{Fe}, \mathrm{Sb}$ and $\mathrm{Zn}$ concentrations ranging from 6 to $41 \mu \mathrm{g} \mathrm{g}^{-1}, 19$ to $109 \mu \mathrm{g} \mathrm{g}^{-1}, 293$ to $701 \mu \mathrm{g} \mathrm{g}^{-1}, 6$ to $43 \mu \mathrm{g} \mathrm{g}^{-1}$ and 21 to $490 \mu \mathrm{g} \mathrm{g}^{-1}$, respectively.

\section{Discussion}

Dryer lint is an heterogeneous assortment of natural and synthetic fibres, human and animal hairs, household dust and various other extraneous solids that have accumulated on clothing and linen and remain after washing and drying. Despite this heterogeneity, the results of the present study have shown that various trace elements are rather homogenously distributed within individual samples, at least over the resolution of the XRF detector $\left(50 \mathrm{~mm}^{2}\right)$. More important are variations both within and between households where samples were taken.

212 Of the elements considered in the present study, $\mathrm{Br}$ and $\mathrm{Sb}$ were frequently encountered in new and 213 washed articles of clothing and Sb was detected in a few samples of linen. Antimony was restricted 214 to articles composed entirely or partly of synthetic, polyester fibres and its presence at, on average, 
about $150 \mu \mathrm{g} \mathrm{g}^{-1}$, may be attributed to the use of $\mathrm{Sb}_{2} \mathrm{O}_{3}$ as a polymerisation catalyst in the manufacture of polyethylene terephthalate, a constituent polymer of polyester (Lacasse and

217 Baumann, 2004). Significantly, four items of clothing (a child's fancy dress outfit and three sports shirts) contained Sb at a concentration exceeding the Ecolabel limit for textiles of 260 ppm (European Commission, 2009).

Concentrations of $\mathrm{Br}$ were more variable among the clothing samples but reasons for its presence are less clear. A common use of brominated compounds in textiles and furnishings is as flame retardants but only certain items of clothing, including young children's night apparel, are flameretarded, and organophosphate compounds appear to be the most favourable choice on health grounds (Lacasse and Baumann, 2004). Moreover, brominated flame retardants are generally used for flame retardancy at much higher concentrations and in conjunction with Sb-based synergists; no statistical association between $\mathrm{Br}$ and $\mathrm{Sb}$ was observed in the clothing samples (Figure 3) and the majority of $\mathrm{Br}$-Sb data for the samples lie below the line defining the mass ratio of these elements in common, commercial flame retardant mixtures (Papazoglou, 2004). In a recent study of brominated compounds in household dust, Peng et al. (2016) found that the majority of brominated compounds were not flame retardants but azo dyes employed as textile colourants. It is surmised, therefore, that $\mathrm{Br}$ in clothing samples analysed in the present study results from a complex assortment of dyes used in both natural and synthetic materials.

With respect to dryer lint, the absence of detectable $\mathrm{Br}$ and $\mathrm{Sb}$ in three dryer lint samples arising from the laundering of cotton towels suggests that there are no significant sources of these elements from the drying equipment itself. Rather, the presence of $\mathrm{Sb}$ and $\mathrm{Br}$ among remaining samples may be largely attributed to the shedding of fibres during washing and drying and, potentially, the dissolution of dyes during washing and their subsequent recombination with other solids; presumably, therefore, the concentration of $\mathrm{Sb}$ or $\mathrm{Br}$ in dryer lint reflects the relative abundance of synthetic fibre-based or Br-dyed articles in the loading. In addition, it is possible that both $\mathrm{Br}$ and $\mathrm{Sb}$ may be present in dryer lint as brominated flame retardants and flame retardant synergists, respectively, derived indirectly from formulations added to soft household furnishings like sofas, mattresses, carpets and curtains, and that have gradually accumulated in household dust (Stapleton et al., 2005).

In contrast, neither $\mathrm{As}$ nor $\mathrm{Pb}$ were detected in articles of clothing or linen indicating that potential phyto-accumulation by natural products or contamination during manufacture are not significant. The frequent detection of $\mathrm{Pb}$ in lint, therefore, may be attributed to the contamination of clothing and linen by extraneous sources. These include household dust and material external to the 
household that is associated with certain activities and occupations and that is readily accumulated by clothing and at least partially resistant to washing. Specifically, $\mathrm{Pb}$ may be derived from internal and external paint flakes while both $\mathrm{Pb}$ and As may be derived from contaminated soil or road dust (Hu et al., 2011; Nezat et al., 2016).

Remaining elements $(\mathrm{Cu}, \mathrm{Fe}, \mathrm{Ni}$ and $\mathrm{Zn})$ display an intermediate profile in that they were present in both clothing-linen, presumably as constituents of dyes, pigments or antimicrobial compounds (Rovira et al., 2015), and dryer lint. However, that the frequency of their detection was greater in lint (see also the semi-quantitative ratios in Table 2) suggests that extraneous, internal and external sources are more important than clothing-linen itself.

The precise trace elemental profile of dryer lint from a given household is likely to reflect a complex number of factors. These include age, location and condition of the property, its proximity to roads or industries, the presence of a garden, the demographics, occupations and activities of its occupants, the presence of any pets, types of flooring and furnishings, frequency of cleaning, and the types of clothes laundered. In a few cases, such factors could be linked to elemental lint profiles in the present study. For example, Pb concentrations were usually (but not always) higher in older properties where lead paint was more likely to be present, high $\mathrm{Br}$ was often associated with households with teenage children, possibly because of the prevalence of a certain type or colour/s of clothing, and Fe and $\mathrm{Zn}$ were elevated in a house where its occupants spent considerable periods outdoors and on bare soil. In other cases, however, it was not possible to attribute elemental profiles to any particular factors. For instance, it was unclear why As was persistently present in just one household (and in six lint samples) and why concentrations of $\mathrm{Cu}$ above $100 \mu \mathrm{g} \mathrm{g}^{-1}$ were only returned for another household (and in three lint samples).

Variations in lint elemental profiles within the same household likely reflect temporal variations in activities and clothing type laundered, as well as the occurrence of isolated practices like decorating and remodelling work or the bulk washing or drying of specific articles. For example, $\mathrm{Br}$ was never detected in lint when towels or tablecloths were laundered but was always present for washes containing articles of clothing, $\mathrm{Pb}$ concentrations were high in one household when external paintwork was being removed, and the highest concentration of $\mathrm{Pb}$ overall was returned when clothes used on fieldwork around historic mine sites were laundered. In addition to providing information on trace element contamination and exposure, the composition of lint samples (and clothing-linen samples) can be used to estimate elemental discharges to the environment via waste water treatment plants through laundering operations. Thus, here it is assumed that the elemental profiles, but not necessarily quantities, of lint (and/or clothing) are 
representative of the elemental profiles of fibres and other material discharged from a domestic washing machine. For elements having a strong extraneous signal in lint, like $\mathrm{As}$, Fe and Pb, discharges are likely to be small compared with other natural and anthropogenic emissions; however, for elements serving as proxies for chemicals whose uses are more specific to textiles and household dust (i.e. $\mathrm{Br}$ and $\mathrm{Sb}$ ), discharges are predicted to be more significant.

There exist various estimates for the amount of fibrous microplastics discharged during clothes washing but on a mass basis, it is assumed that $0.3 \%$ of the loading is lost through wash water (Hartline et al., 2016). An average washing load of $2.6 \mathrm{~kg}$, a typical annual number of washes per individual of 79 (Sillanpää and Sainio, 2017) and a population of 60.02 million yields an emission of just over 40 million $\mathrm{kg}$ of fibrous material for the UK per year. Combining this with a lint concentration of $\mathrm{Sb}$ (largely as $\mathrm{Sb}_{2} \mathrm{O}_{3}$ ) of $25 \mu \mathrm{g} \mathrm{g}^{-1}$ based on concentrations returned by the XRF (Table 2), its detection frequency and its detection limit, results in an annual discharge of about 1000 $\mathrm{kg}$. For $\mathrm{Br}$ (as brominated compounds), an equivalent figure of about $1200 \mathrm{~kg}$ is derived from an average $\mathrm{Br}$ concentration in lint of $30 \mu \mathrm{g} \mathrm{g}^{-1}$ (Table 2). Alternative estimates may be derived from a representative mass of polyester lost per wash (340 mg; Sillanpää and Sainio, 2017) and the respective concentrations of $\mathrm{Sb}$ and $\mathrm{Br}$ in synthetic or part-synthetic clothing of $160 \mu \mathrm{g} \mathrm{g}^{-1}$ and 170 $\mu \mathrm{g} \mathrm{g} \mathrm{g}^{-1}$, respectively; here, computed annual discharges are fourfold lower than previous estimates at $260 \mathrm{~kg}$ for $\mathrm{Sb}$ and $275 \mathrm{~kg}$ for $\mathrm{Br}$.

The discrepancies in these estimates clearly reflect significant inter-sample variations in chemical makeup, limitations in the assumptions about the relationship between washing machine discharge and lint composition, the presence of additional (non-clothing) sources of $\mathrm{Sb}$ and $\mathrm{Br}$ (e.g. flame retardants in household dust) and uncertainties associated with estimates of fibre loss during washing (which appears to have a complex dependency on washing conditions and type and age of garments). Nevertheless, they illustrate that the loss of $\mathrm{Sb}$ and brominated compounds through this route and in association with microfibers is potentially significant. The ultimate fate of these compounds will depend on the type and efficiency of waste water treatment but in the UK current practices ensure that varying fractions are discharged into the aquatic environment and retained for agricultural sludge.

In conclusion, portable XRF has proved to be a rapid and convenient means of determining various trace elements in dryer lint as a proxy for contamination in the household or arising from activities of its occupants and for evaluating the elemental composition of microfibres discharged to the environment from laundering activities. Specifically, $\mathrm{Br}$ and $\mathrm{Sb}$ appear to reflect the nature of 
clothing being laundered while $\mathrm{As}$ and $\mathrm{Pb}$ appear to be more representative of contamination that is both internal and external to the household.

\section{Acknowledgements}

The various participants of the study are acknowledged for supplying lint samples and details of their collection. Billy Simmonds and Andy Arnold (UoP) are thanked for the preparation and analysis of lint digests.

\section{References}

Almroth, B.M.C., Astrom, L., Roslund, S., Petersson, H., Johnasson, M., Persson, N.K., 2018. Quantifying shedding of synthetic fibersd from textiles; a source of microplastics released into the environment. Environmental Science and Pollution Research 25, 1191-1199.

Bull, A., Brown, M.T., Turner, A., 2017. Novel use of field-portable-XRF for the direct analysis of trace elements in marine macroalgae. Environmental Pollution 220, 228-233.

European Commission, 2009. Commission decision of 9 July 2009 establishing the ecological criteria for the award of the Community Ecolabel for textile products. 2009/567/EC. Official Journal of the European Union L197, 70-86.

Ene-Parent, J., Zikovsky, L., 2001. Neutron activation analysis of laundry dryer lint. Journal of Radioanalytical and Nuclear Chemistry 247, 197-198.

Hartline, N.L., Bruce, N.J., Karba, S.N., Ruff, E.O., Sonar, S.U., Holden, P.A., 2016, Microfiber masses recovered from conventional machine washing of new or aged garments. Environmental Science and Technology 50, 11532-11538.

Hernandez, E., Nowack, B., Mitrano, D.M., 2017. Polyester textiles as a source of microplastics from households: A mechanistic study to understand microfiber release during washing. Environmental Science and Technology 51, 7036-7046.

Hu, X., Zhang, Y., Luo, J., Wang, T.J., Lian, H.Z., Ding, Z.H., 2011. Bioaccessibility and health risk of arsenic, mercury and other metals in urban street dusts from a mega-city, Nanjing, China.

Environmental Pollution 159, 1215-1221.

Lacasse, K., Baumann, W., 2004. Textile chemicals: Environmental data and facts. Springer-Verlag, Berlin. 1180pp.

Mahaffy, P.G., Martin, N.I., Newman, K.E., Hohn, B., Mikula, R.J., Munoz, V.A., 1998. Laundry dryer lint: A novel matrix for nonintrusive environmental lead screening. Environmental Science and Technology 32, 2467-2473.

Massos, A., Turner, A., 2017. Cadmium, lead and bromine in beached microplastics. Environmental Pollution 227, 139-145. 
Nezat, C.A., Hatch, S.A., Uecker, T., 2017, Heavy metal content in urban and park soils: A case study in Spokane, Washington, USA. Applied Geochemistry 78, 186-193.

Niton, 2011. Thermo Fisher Scientific Niton Analyzers: XL3 Analyzer User's Guide, version 7.2. Thermo Scientific, Billerica, MA, 650pp.

Ouyang, X., Weiss, J.M., de Boer, J., Lamoree, M.H., Leonards, P.E.G., Non-target analysis of household dust and laundry dryer lint using comprehensive two-dimensional liquid chromatography coupled with time-of-flight mass spectrometry. Chemosphere 166, 431-437.

Papazoglou, E.S., 2004. Flame retardants for plastics. In: Handbook of Building Materials for Fire Protection, Harper, C.A., ed, McGraw-Hill, New York.

Peng, H., Saunders, D.M.V., Sun, J., Jones, P.D., Wong, C.K.C., Liu, H., Giesy, J.P., 2016. Mutagenic azo dyes, rather than flame retardants, are the predominant brominated compounds in house dust. Environmental Science and Technology 50, 12669-12677.

Rovira, J., Nadal, M., Schumacher, M., Domingo, D.L., 2015. Human exposure to trace elements through the skin by direct contact with clothing: Risk assessment. Environmental Research 140, 308316.

Sillanpää, M., Sainio, P., 2017. Release of polyester and cotton fibers from textiles. Environmental Science and Pollution Research 24, 19313-19321.

Stapleton, H.M., Dodder, N.G., Offenberg, J.H., Schantz, M.M., Wise, S.A., 2005. Polybrominated diphenyl ethers in house dust and clothes dryer lint. Environmental Science and Technology 39, 925931.

Turner, A., Solman, K.R., 2016. Analysis of the elemental composition of marine litter by fieldportable-XRF. Talanta 159, 262-271. 
Table 1: The number of cases in which the different trace elements were detected in dryer lint $(n)$ 373 and summary statistics of elemental concentrations, where detected, in $\mu \mathrm{g} \mathrm{g}^{-1}$ dry weight. Note that 374 data are shown in terms of both number of households (19) and number of samples (70) where 375 elements were detected.

\begin{tabular}{lcccccccc}
\hline & $\mathrm{As}$ & $\mathrm{Br}$ & $\mathrm{Cu}$ & $\mathrm{Fe}$ & $\mathrm{Ni}$ & $\mathrm{Pb}$ & $\mathrm{Sb}$ & $\mathrm{Zn}$ \\
\hline$n$ (houses) & 1 & 19 & 17 & 19 & 6 & 10 & 7 & 19 \\
mean & 67.2 & 33.8 & 69.8 & 631.0 & 44.7 & 27.5 & 56.5 & 340 \\
sd & & 48.4 & 53.0 & 640.1 & 16.7 & 29.7 & 17.9 & 469 \\
median & & 18.0 & 60.7 & 323.4 & 41.0 & 14.9 & 51.6 & 239 \\
$\min$ & & 8.6 & 33.8 & 128.3 & 29.5 & 8.3 & 39.2 & 39.7 \\
$\max$ & & 213 & 264 & 2397 & 72.8 & 108 & 89.4 & 2160 \\
& & & & & & & & \\
$n$ (samples) & 6 & 62 & 46 & 65 & 6 & 20 & 8 & 70 \\
mean & 67.2 & 27.2 & 70.4 & 544.5 & 44.7 & 23.4 & 55.2 & 282.3 \\
sd & 90.5 & 33.4 & 65.4 & 637.4 & 16.7 & 22.6 & 17.1 & 555.5 \\
median & 33.0 & 16.2 & 57.9 & 264.9 & 41.0 & 15.1 & 50.5 & 96.9 \\
min & 10.8 & 5.5 & 28.7 & 76.1 & 29.5 & 7.5 & 39.2 & 24.2 \\
max & 249 & 213 & 456 & 3590 & 72.8 & 108 & 89.4 & 3540 \\
\hline
\end{tabular}

379 Table 2: The number of samples of clothing-linen in which trace elements were detected $(n)$ and 380 summary statistics of elemental concentrations, where detected, in $\mu \mathrm{g} \mathrm{g}^{-1}$ dry weight. Also shown is 381 the ratio of the sum of concentrations in clothing-linen and dryer lint for each element.

\begin{tabular}{|c|c|c|c|c|c|c|c|c|}
\hline & As & $\mathrm{Br}$ & $\mathrm{Cu}$ & $\mathrm{Fe}$ & $\mathrm{Ni}$ & $\mathrm{Pb}$ & $\mathrm{Sb}$ & $\mathrm{Zn}$ \\
\hline$n$ & 0 & 32 & 5 & 25 & 1 & 0 & 35 & 9 \\
\hline mean & & 169 & 43.0 & 135 & 13.3 & & 164 & 964 \\
\hline sd & & 297 & 16.5 & 216 & & & 85.7 & 1090 \\
\hline median & & 36.4 & 39.0 & 89.2 & & & 146 & 882 \\
\hline $\min$ & & 3.5 & 22.2 & 42.1 & & & 44.0 & 33.4 \\
\hline $\max$ & & 13,400 & 67.2 & 1150 & & & 476 & 3310 \\
\hline $\begin{array}{l}\Sigma \text { [clothing-linen] / } \\
\Sigma[\text { dryer lint }]\end{array}$ & 0 & 3.2 & 0.07 & 0.10 & 0.05 & 0 & 13.0 & 0.44 \\
\hline
\end{tabular}


Figure 1: A selection of dryer lint samples in 21-mm diameter XRF cups that had been collar-sealed 385 with polyester film.

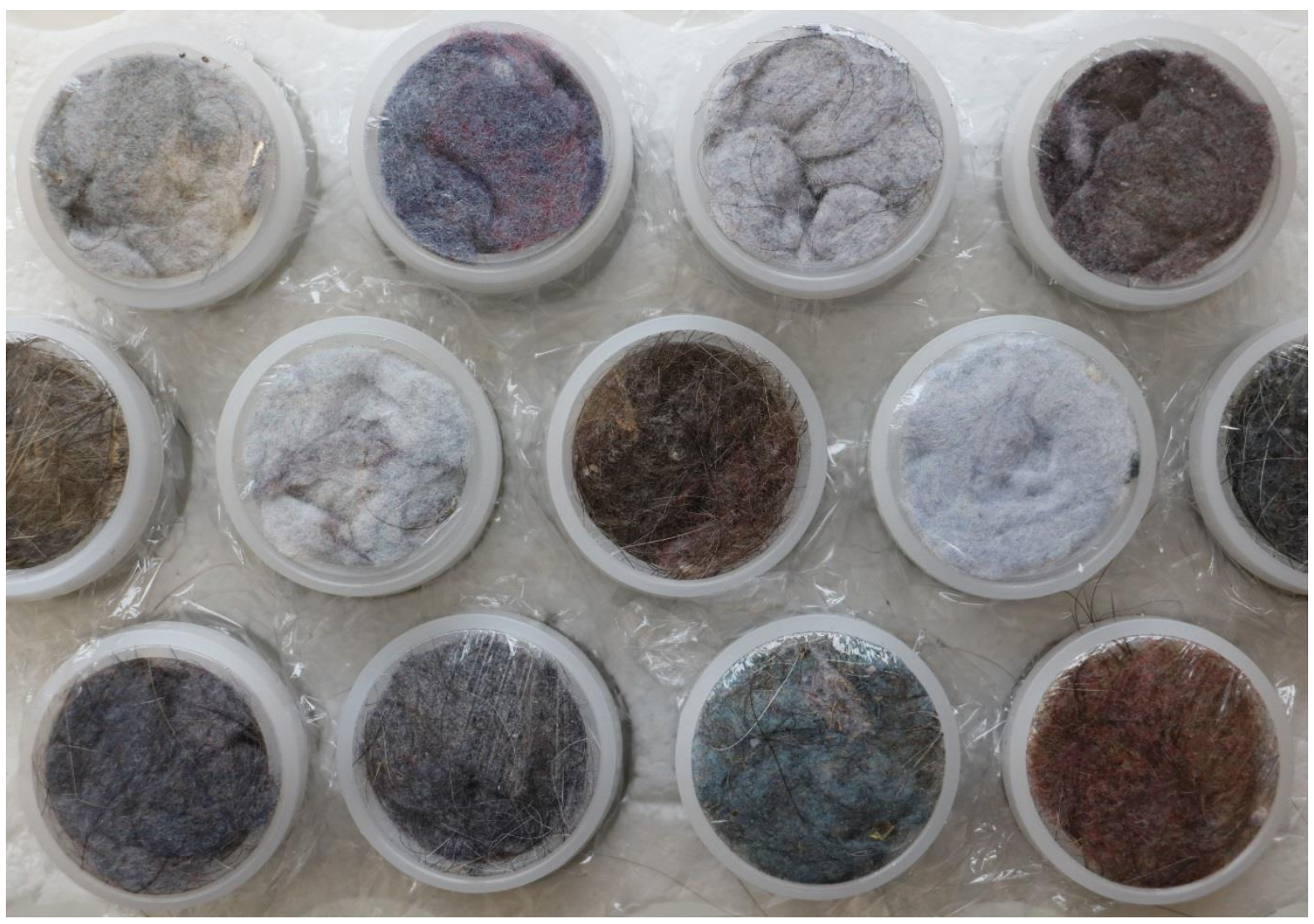

386 
Figure 2: A comparison of elemental concentrations in five samples of dryer lint determined by XRF and by ICP following acid digestion. Note that $\mathrm{As}, \mathrm{Cu}, \mathrm{Ni}, \mathrm{Pb}$ and $\mathrm{Sb}$ were not detected by XRF in some or all samples.

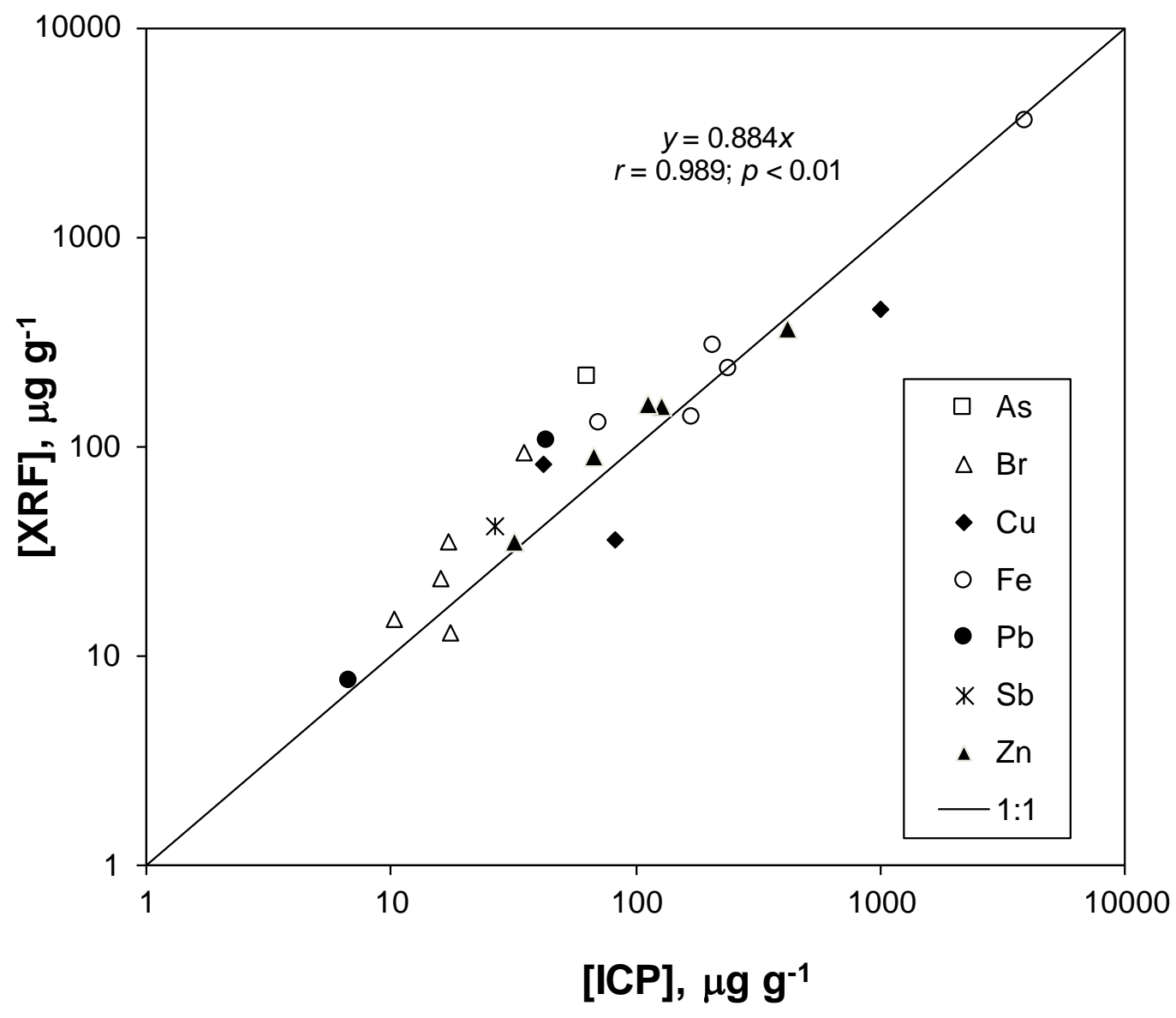

393 
Figure 3: Concentrations of $\mathrm{Br}$ versus concentrations of $\mathrm{Sb}$ in articles of clothing $(\bullet)$ and samples of dryer lint (o). The solid line shows the representative mass ratio of $\mathrm{Br}$ to $\mathrm{Sb}$ in common brominated flame retardant mixtures (Papazoglou, 2004).

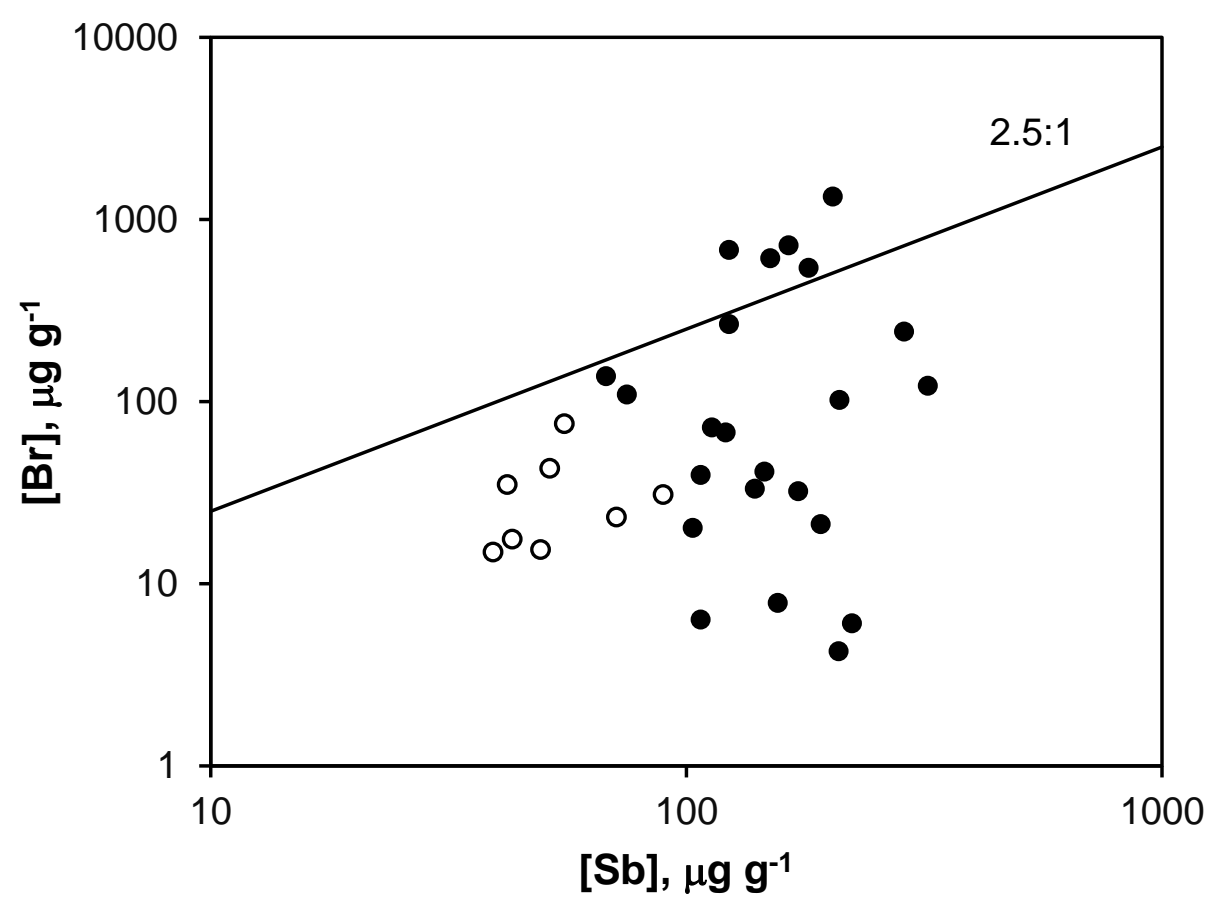

408 